\title{
Núcleos de Atendimento no Ifsul - Câmpus Pelotas: Uma reflexão sobre as Políticas Educacionais voltadas à diversidade acadêmica
}

\author{
Centros de Servicio de Ifsul - Campamentos Pelotas: Una reflexión sobre \\ las Políticas Educativas relativas a la diversidad académica
}

\author{
Ifsul Service Centers - Pelotas Camps: A reflection on Educational \\ Policies concerning academic diversity
}

Vivian Bonow Boeira1

Jair Jonko Araujo 2

\begin{abstract}
Resumo
$\mathrm{O}$ artigo refere-se a uma pesquisa de mestrado, em andamento, que tem por intuito investigar as estratégias utilizadas no IFSul - Câmpus Pelotas para colocar em prática as políticas afirmativas implantadas no Brasil relativas à inclusão. Busca-se, assim, compreender as ações voltadas em prol das diversidades, especificamente políticas voltadas para questões étnico-raciais, de deficiências físicas e de gênero, considerando o trabalho de três Núcleos de Atendimento - Núcleo de Apoio às Pessoas com Necessidades Específicas (NAPNE), Núcleo de Gênero e Diversidade (NUGED) e Núcleo de Estudos Afro-brasileiros e Indígenas (NEABI). A pesquisa propõe uma abordagem qualitativa, com referencial de Bogdan e Biklen (1994). A compreensão do contexto tem por base o levantamento documental, a partir de leis, decretos, documentos institucionais, entre outros textos que culminaram na regulação dessas práticas. De modo a compreender quais são as negociações, conflitos, influências e estratégias para as decisões e ações que envolvem discentes e servidores, no âmbito do Câmpus Pelotas, serão realizadas, na continuidade da pesquisa, entrevistas semiestruturadas com sujeitos participantes dos núcleos. O estudo encontra-se ainda em fase inicial, correspondente ao diagnóstico do contexto.
\end{abstract}

Palavras-chave: Diversidade; Inclusão; Núcleos; Políticas Afirmativas; Práticas.

\section{Resumen}

El artículo se refiere a una investigación de maestría en curso, cuyo objetivo es investigar las estrategias utilizadas en IFSul - Campus Pelotas para poner en práctica las políticas afirmativas implementadas en Brasil con respecto a la inclusión. Por lo tanto, buscamos comprender las acciones dirigidas a la diversidad, específicamente las políticas centradas en cuestiones étnico-raciales, discapacidades físicas y género, considerando el trabajo de tres Centros de Servicio: Centro de Apoyo para Personas con Necesidades Específicas (NAPNE), Centro de Género y Diversidad (NUGED) y Centro de Estudios Afrobrasileños e Indígenas (NEABI). La investigación propone un enfoque cualitativo, con referencia de Bogdan y Biklen (1994). La comprensión del contexto se basa en la encuesta documental, a partir de leyes, decretos, documentos institucionales, entre otros textos que culminaron en la regulación de estas prácticas. Con el fin de comprender cuáles son las negociaciones, conflictos, influencias y estrategias para las decisiones y acciones que involucran a estudiantes y servidores, dentro del alcance del Campus de Pelotas, se llevarán a cabo entrevistas semiestructuradas con los sujetos que participan en el núcleo. El estudio aún se encuentra en su fase inicial, correspondiente al diagnóstico de contexto.

Palabras-clave: Diversidad; Inclusión; Núcleos; Políticas afirmativas; Practicas.

\footnotetext{
${ }^{1}$ Mestranda do Mestrado Profissional em Educação e Tecnologia; Instituto Federal Sul-rio-grandense; Pelotas, RS, Brasil; bonowvivian@gmail.com.

${ }^{2}$ Doutor em Educação; Instituto Federal Sul-rio-grandense; Pelotas, RS, Brasil; jairaraujo@ifsul.edu.br.
} 


\begin{abstract}
The article refers to an ongoing master's research, which aims to investigate the strategies used in IFSul Campus Pelotas to put into practice the affirmative policies implemented in Brazil regarding inclusion. Thus, we seek to understand the actions aimed at diversity, specifically policies focused on ethnic-racial issues, physical disabilities and gender, considering the work of three Service Centers - Support Center for People with Specific Needs (NAPNE). Gender and Diversity Center (NUGED) and Center for Afro-Brazilian and Indigenous Studies (NEABI). The research proposes a qualitative approach, with reference from Bogdan and Biklen (1994). The understanding of the context is based on the documentary survey, from laws, decrees, institutional documents, among other texts that culminated in the regulation of these practices. In order to understand what are the negotiations, conflicts, influences and strategies for decisions and actions involving students and servants, within the scope of the Pelotas Campus, semi-structured interviews with subjects participating in the nucleus will be carried out. The study is still in its initial phase, corresponding to the context diagnosis.
\end{abstract}

Keywords: Diversity; Inclusion; Cores; Affirmative Policies; Practices.

\title{
1. Introdução
}

A educação é um instrumento para a construção da cidadania. Nesse sentido, grande parte da sociedade acredita que a escola é fundamental para a formação dos sujeitos. O ambiente escolar, como espaço heterogêneo, principalmente o público, traz cada vez mais a multiplicidade de indivíduos que, antes da regulação de leis e democratização do ensino, eram segregados dos espaços urbanos e de alguns meios sociais.

Estudos preliminares, por meio do mapeamento de produções acadêmicas no Banco de Teses e Dissertações da Capes, relacionadas ao objeto desta pesquisa, apontam que a obrigatoriedade da inclusão de determinadas populações, nas instituições de ensino, a partir das políticas educacionais voltadas para as minorias, vem provocando reflexões sobre a desnaturalização de algumas ações e discursos tradicionalmente partilhados pela sociedade e a percepção de como a ideia de "conduta" é um mecanismo de coerção na cultura escolar.

As primeiras políticas relacionadas à educação inclusiva, no Brasil, apresentadas na Política Nacional de Educação Especial (HÜSKEN, 2000), apresentam, entre os princípios específicos aos portadores de necessidades especiais, a capacitação de recursos humanos e a remoção de barreiras de qualquer natureza. No entanto, o documento enuncia que a construção real é o resultado do que é possível fazer, uma adaptação da norma, considerando sujeitos e contextos.

Anteriormente a essa Política, o documento "Educação Para Todos" (1990) já apresentava a questão da Educação Inclusiva para os Portadores de Necessidades Educativas Especiais - PNEEs (terminologia utilizada à época). Porém, não só a eles se limita, pois abrange grupos minoritários e de desvantagem que não podem ser excluídos do processo 
educacional. Assim, a ideia de inclusão faz referência a todos/as que têm sofrido processos de exclusão educacional e social decorrentes de diferenças culturais, sociais, étnico-raciais, religiosas, de gênero e outras. As necessidades educacionais especiais concernem toda e qualquer necessidade específica apresentada pelos/as estudantes no decorrer do processo de escolarização.

Nessa perspectiva, o trabalho é um recorte da pesquisa de mestrado, em andamento, e tem o intuito de apresentar o caminho metodológico a fim de analisar a construção dos Núcleos de Atendimento dentro do Instituto Federal Sul-rio-grandense (IFSul) a partir do referencial teórico do Ciclo de Políticas de Stephen Ball, considerando especificamente os textos, discursos e práticas das políticas públicas inclusivas. Elegeu-se como objetivo principal investigar as principais ações dos Núcleos de Atendimento - NAPNE, NEABI e NUGED - no IFSul - Câmpus Pelotas voltadas para a consolidação das políticas afirmativas. Neste texto, buscamos, especificamente, compreender a construção das políticas afirmativas no Brasil; e entender o processo de construção dos Núcleos de ações afirmativas neste câmpus.

Em princípio, será apresentada a justificativa que fundamenta o estudo, bem como a metodologia que será adotada. Posteriormente, discutiremos as concepções que alicerçam o Ciclo de Políticas de Stephen Ball, cujos conceitos dos contextos serão usados para examinar as práticas dos Núcleos de Atendimento. E, por fim, o conceito de políticas afirmativas, a sua importância no Brasil e a construção dos núcleos nos Institutos Federais.

\section{Interesse pela temática}

Entendendo a importância do papel do professor não só na construção do conhecimento, mas como educador, a escolha da pesquisa é também uma consequência da experiência como docente em escolas de ensino básico. Alguns conflitos e dilemas, que ocorriam em sala de aula, eram um reflexo de discursos preconceituosos de grupos dominantes em relação à conduta e a aparência de outros. Quando essas problemáticas extrapolavam o limite da sala de aula, os núcleos responsáveis pelo Serviço de Orientação Educacional (SOE) e Serviço de Coordenação de Turno (SCT) eram acionados.

Geralmente, o primeiro, tendo como foco a orientação psicológica, oferecia um trabalho mais individual, trabalhando com demandas particulares; o outro lidava, na maioria das vezes, com questões de indisciplina dentro e fora da sala de aula. Problemas referentes à exclusão, discriminação e preconceito entravam na pauta do tema "bullying" e eram 
trabalhados em aula e "contornados" com abordagens pontuais nas turmas cujas problemáticas eram mais visíveis na instituição.

Com a obrigatoriedade da inclusão de pessoas com deficiência nas escolas regulares, receberam-se alguns alunos com síndrome de down e com outros problemas de aprendizagem. No entanto, os professores não haviam sido capacitados para isso, tampouco havia um auxiliar de apoio para esses estudantes. Nesse contexto, entendo que não existia inclusão no que se refere à aprendizagem.

Ao começar a trabalhar como servidora pública no IFSul - Câmpus Pelotas, pude perceber que havia mais vozes, movimentos e ações em relação à inclusão e ao respeito às diversidades. Isso provocou em mim o desejo de investigar a efetivação das políticas de inclusão dos três núcleos a partir da atuação e sob a ótica dos sujeitos que constituíam esses meios, para poder perceber, consequentemente, as fragilidades e potencialidades de políticas e ações voltadas para assegurar a inclusão.

A escola é um espaço que categoriza o indivíduo como uma forma de identificação e o faz sujeito por meio das interações com os outros. Nessa perspectiva, a imposição dos Núcleos, em razão das políticas oficiais de inclusão, problematiza a naturalização de certas ações, discursos e modos de ser e vão de encontro à imposição das normas dominantes de conduta, sexualidade, poder econômico e aparência (FOUCAULT, 2009).

A partir de meus estudos e reflexões, assumo a relevância da construção e produção de políticas voltadas para a descentralização da gestão escolar. Assim, ao observar as situações que operam no contexto institucional, veem-se processos de mudança nos espaços, nos debates e ações em relação às questões relacionadas à inclusão. Outra questão essencial, para o interesse sobre o assunto, foi a participação em um curso de capacitação de servidores sobre educação inclusiva e atendimento educacional cujo programa trazia um panorama histórico de leis em um contexto da macro e micropolítica. Nesse sentido, os estudos referentes aos textos trabalhados acrescentaram e aprofundaram reflexões anteriores sobre a concepção de inclusão de sujeitos não só com necessidades especiais, mas também aqueles que sofrem algum tipo de discriminação.

\subsection{Percurso Metodológico}

O estudo será realizado nos Núcleos de Atendimento do IFSul - Câmpus Pelotas e propõe uma abordagem qualitativa.

A abordagem qualitativa deste estudo tem como referencial Bogdan e Biklen (1994); dessa maneira, embasou-se nas cinco características das pesquisas qualitativas enunciadas 
pelos autores: (1) a fonte direta dos dados é o ambiente natural e o investigador é o principal agente na exploração desses elementos; (2) os dados são de caráter descritivo; (3) o interesse pela pesquisa é constituído não só pelos resultados, mas também pelo processo; (4) a análise dos dados é feita de forma indutiva; e (5) o interesse do pesquisador em compreender o sentido que os sujeitos dão às suas vivências.

Segundo Bogdan e Biklen (1994, pág. 16), podemos considerar os dados como qualitativos quando descrevem pessoas, locais e conversas, e as questões investigadas já são formuladas previamente para compreender os fenômenos de acordo com sua complexidade e contexto natural, privilegiando a observação dos fenômenos com o foco nos sujeitos da investigação. No caso da pesquisa, a estratégia para essa compreensão é a entrevista em profundidade. Ademais, esses dados permitem que o investigador desenvolva seu ponto de vista sobre como os sujeitos analisados interpretam determinados aspectos e realidades, sem juízo de valor.

Os dados são simultaneamente as provas e as pistas. Coligidos cuidadosamente servem como factos inegáveis que protegem a escrita que possa ser feita de uma especulação não fundamentada. Os dados ligam-nos ao mundo empírico e, quando sistemáticos e rigorosamente recolhidos, ligam a investigação qualitativa a outras formas de ciência. Os dados incluem os elementos necessários para pensar de forma adequada e profunda acerca dos aspectos da vida que pretendemos explorar. (BOGDAN ; BIKLEN, 1994, pág. 149)

Consequentemente, as entrevistas podem contribuir para compreender quais são as negociações, conflitos, influências e estratégias para as decisões e ações que envolvem discentes e servidores. Por isso, essa perspectiva de estudo poderá apresentar de forma mais expressiva as ações desenvolvidas dentro do ambiente. Ademais, a partir das políticas educacionais voltadas para as minorias, perceber a reestruturação da cultura escolar e das concepções de identidade na escola, detectando os principais problemas que envolvem a diversidade.

A fim de entender o método da análise textual-discursiva, Moraes e Galiazzi (2016) conceitua Fenomenologia como uma Filosofia e um método ligados à abordagem direta dos fenômenos e "coloca o homem como centro de sua pesquisa" (pág. 24). Além disso, entende que o homem é o criador de sua realidade, e a linguagem é um instrumento fundamental para expressar as suas percepções sobre o mundo.

De acordo com Moraes e Galiazzi (2016), é necessário compreender não só os fatos, mas a essência do ser.

O ser reside na linguagem. Esta é sua casa. Investigar a linguagem é, portanto, investigar o próprio ser, tendo a fala o poder efetivo de traduzir a essência do ser e dos fenômenos. Por essa razão a pesquisa fenomenológica vale-se essencialmente das manifestações orais e escritas dos sujeitos. É da análise destas que a pesquisa fenomenológica extrai as essências dos fenômenos investigados. (pág. 29) 
Partindo da base teórica descrita, apresenta-se, a seguir, o caminho que será percorrido nesta investigação. Em princípio, haverá um levantamento documental, como leis, decretos, documentos institucionais, entre outros textos da macro e micropolítica que culminaram na institucionalização dos Núcleos de Atendimento. Entre alguns documentos fundamentais da Legislação Brasileira estão a Constituição Federal de 1988, Lei de Diretrizes e Bases da Educação Nacional (LDBN 939496), Política Nacional de Educação Especial na Perspectiva da Educação Inclusiva (2008) e o Plano Nacional de Educação (2014). Em relação aos documentos institucionais, consideram-se relevantes o Plano de Desenvolvimento Institucional que vigora no momento (2014 - 2019), o Projeto Pedagógico Institucional, o Regimento Interno da instituição, bem como os regimentos e regulamentos que estabelecem o funcionamento dos núcleos.

A pesquisa terá como sujeitos participantes dois representantes de cada núcleo, um que tenha participado da consolidação dessas políticas e outro que esteja atuando neste momento. Nesse contexto, os sujeitos de interesse da pesquisa são os participantes dos núcleos - três sujeitos que tenham participado da inserção dos núcleos e três sujeitos que estejam, hoje, atuando nesses espaços. Como a intenção da investigação é sobre a atuação dos núcleos na percepção de servidores que atuam nas práticas das ações afirmativas dentro do Câmpus, recai sobre esses sujeitos a competência de opinar acerca do desempenho e a efetivação das PA.

\section{Ciclo de Políticas como ferramenta para análise das políticas de inclusão}

De forma a analisar as políticas públicas de inclusão, tomou-se como aporte teóricometodológico o Ciclo de Políticas de Stephen Ball e seus colaboradores, que considera contextos da macro e micropolítica. Esses contextos permitem compreender como a política é pensada, os textos que a traduzem, as práticas e seus efeitos e resultados.

A política, segundo Ball (1994), pode ser entendida como texto e discurso, e uma está implícita na outra. Desse modo, pode-se apreender que existem alguns discursos apresentados nos textos legais cujas vozes foram autorizadas, por meio de negociações e influências, para que legitimassem algumas políticas públicas no âmbito da educação. No entanto, ao colocálas em prática, a gestão e servidores, de modo geral, deverão adequá-las de acordo com os espaços e atores do contexto, o que é possibilitado pelos explícitos e implícitos oriundos dos discursos.

Em princípio, Ball estabeleceu três contextos essenciais para a formulação de uma política: Contexto de Influência, Contexto da Produção de Textos e Contexto da Prática. 
Posteriormente, Ball e seus colaboradores integraram à teoria o Contexto dos Resultados e de seus Efeitos e o Contexto da Estratégia. O quarto Contexto do ciclo de políticas - o de Resultados ou de seus Efeitos - direciona suas preocupações para questões relacionadas com a justiça, com a igualdade e com a liberdade entre as pessoas. Já o Contexto da Estratégia Política tem como foco relacionar a formulação de estratégias para as atividades sociais e políticas que efetivamente vão lidar com as desigualdades criadas ou reproduzidas pela política investigada.

Ball (1994) evidencia que a construção de uma política depende de fatores contextuais, históricos e socioculturais. Desse modo, há uma grande diferença entre o registro legal e sua implementação. A Teoria da Atuação, construída pelo autor e seus colaboradores em seus estudos do Ciclo de Políticas, apresenta a política como texto e como discurso. Entretanto, uma não é oposta à outra, mas sim estão implícitas uma na outra, processos que terão sentido a partir do próprio leitor, das ações e seus efeitos.

Outro ponto relevante do Ciclo de Políticas de Ball é a questão de se considerar as leis dentro de um contexto macro e, posteriormente, adaptá-lo dentro de um contexto escolar, em uma determinada região com suas peculiaridades, cujos processos culturais estão em constante movimento. Mainardes (2006) cita o Ciclo de Políticas de Ball enfatizando esse processo:

Esta abordagem destaca a natureza complexa e controversa da política educacional, enfatiza os processos micropolíticos e a ação dos profissionais que lidam com as políticas no nível local e indica a necessidade de se articularem os processos macro e micro na análise de políticas educacionais. Esse referencial teórico-analítico não é estático, mas dinâmico e flexível (pág. 49)

Ainda que haja muitos instrumentos políticos com poder jurídico para promover a cidadania, há também muitos problemas nos meios educacionais, já que apenas algumas "vozes" são ouvidas e respaldadas de autoridade, ou seja, aqueles discursos impostos pela macropolítica (governos) e/ou pela micropolítica (gestão escolar). Consequentemente, para Ball (1994), os discursos são um instrumento e um efeito do poder, mas podem também ser um ponto de resistência e oposição, dependendo das possibilidades.

Levando em consideração o exposto, a sala de aula e os espaços de convivência e auxílio para os alunos são onde realmente os projetos políticos serão vivenciados. Segundo Mainardes (2006), os efeitos das políticas podem representar mudanças reais, como justiça, igualdade e liberdade individual. Para tanto, é imprescindível impactos no currículo, pedagogia, avaliação e organização da instituição. Vê-se que, em alguns casos, a fim de que haja a implantação de novas práticas, ainda há muito a avançar, pois limitações de verbas para 
a infraestrutura física e qualificação da equipe, além de rigidez da estrutura pedagógica, fazem-se presentes nesses contextos, como evidenciado pelo autor:

[...] o foco da análise de políticas deveria incidir sobre a formação do discurso da política e sobre a interpretação ativa que os profissionais que atuam no contexto da prática fazem para relacionar os textos da política à prática. Isso envolve identificar processos de resistência, acomodações, subterfúgios e conformismo dentro e entre as arenas da prática, e o delineamento de conflitos e disparidades entre os discursos nessas arenas. (MAINARDES, 2006, pág. 50)

Há algumas décadas, o governo se encarregou da promoção da economia. O novo acordo político global trouxe também o espírito empresarial, competição e excelência, deslegitimando a justiça social, equidade e tolerância. A ideia de perfomatividade vem transformando o trabalho com conhecimento das instituições públicas em "resultados", níveis de "desempenho" e "formas de qualidade". A responsabilização vem reduzindo o ensino e a aprendizagem a processos de produção e de fornecimento; logo, cumprindo os objetivos de mercado eficiente e de controle de qualidade. (BALL, 2004)

Como danos colaterais, Ball (2004) enfatiza uma deterioração do princípio de identidade de forma que as especificidades das interações humanas são apagadas. Além disso, os pontos de vista das classes estão articulados no interior dos discursos e regimes políticos mutáveis ("sociedade de mercado" e estética de consumo). Por fim, os valores e incentivos das políticas de mercado legitimam compromissos e ações - empreendimento, competição e excelência - ao mesmo tempo que inibem outros - justiça, equidade, tolerância.

Dentre os contextos explorados pelo autor, dois deles têm potencial para uma análise dos Núcleos de Atendimento: Contexto de Influência e o Contexto da Prática. O primeiro analisa onde a política gera efeitos e como as consequências podem ser distintas do que foi conjecturado na política original, ou seja, como a reinterpretação foi feita pelos profissionais no nível micro. Já a segunda apresenta como são iniciadas e construídas as políticas, abrangendo as disputas de poder (grupos sociais, sindicatos, governos e outros grupos de interesse) e a formação e legalidade de um discurso.

\section{As Políticas Afirmativas no Brasil}

Neste trabalho, opta-se por discutir a construção das políticas afirmativas no Brasil a partir de produções acadêmicas do Banco de Teses e Dissertações da Capes que abordam esta temática. Sob o prisma dos objetivos, as pesquisas selecionadas, a fim de compor o material bibliográfico, contribuirão para fomentar a discussão sobre as PA, no Brasil, que podem garantir a inclusão das diversidades sociais marginalizadas por séculos e excluídas na sociedade e na escola. Após a coleta e análise de material, delineiam-se as primeiras impressões a respeito de pesquisas acadêmicas sobre a temática. 
A princípio, como critérios de limitação da pesquisa, definiram-se quatro descritores para busca no banco de dados: Política(s) Afirmativa(s), Inclusão, Educação e Núcleo. Preliminarmente foram selecionados 185 trabalhos. A partir da leitura do título e dos resumos, foram inclusos 16 trabalhos, considerados com conteúdo expressivo para auxiliar nos estudos.

Esses trabalhos foram examinados por seus capítulos, que deveriam conter aprofundamento teórico. Desses estudos, pôde-se chegar ao número de 6 teses e 3 dissertações, compondo um total de 9 trabalhos que farão parte do corpus de análise da pesquisa. Para fins de apresentar uma visão geral neste artigo, compreender os conceitos de políticas afirmativas e mudanças ocorridas nos últimos anos nos institutos federais, foram escolhidos três trabalhos condicionados à perspectiva da pesquisadora, que considerou seu pré-conhecimento sobre a instituição e as ações praticadas a partir das políticas impostas em razão das leis de inclusão.

Ao tecer uma reflexão sobre políticas afirmativas, deve-se, em um primeiro momento, compreender as disparidades sociais em todos os segmentos. Desse modo, as políticas sociais buscam garantir a igualdade prevista na Constituição. No entanto, tratar na mesma proporção de igualdade as pessoas que nos meios sociais têm seus direitos negados em razão de uma característica que as exclui, é continuar mantendo essa problemática histórica.

No cotejo analítico do papel do Estado é importante destacar que o mesmo possui dever de agir. Portanto, sua atuação possui caráter abrangente, não podendo sua atividade ficar indiferente às questões sociais, essencialmente a miséria. Faz-se mister mencionar que o cidadão, igualmente, deve ser envolvido na atuação estatal, para que o mesmo se sinta parte de um projeto nacional, com o compartilhamento das melhorias e das responsabilidades, orientados pela vontade comum, que busque a justiça social em sua plenitude. (HIPPLER, 2015, pág. 28)

Desse modo, o acesso à educação e o aperfeiçoamento profissional são imprescindíveis para que haja, pelo menos em parte, justiça social, uma vez que esse fator contribui para o desenvolvimento do ser humano. Vale acrescentar que, no contexto das políticas neoliberais, considerando a educação como um alívio à pobreza, o Brasil democratizou o acesso ao ensino superior, mas sem focar em projetos e investimentos na educação básica e na formação e qualificação dos professores.

Apesar de o país ter buscado cumprir, por meio de reformas educativas e elaboração de políticas públicas voltadas a mudanças nos serviços educativos nas últimas décadas, ainda se percebe a fragilidade e o pouco aprimoramento dentro de grande parte das instituições no que tange aos direitos sociais assegurados na Constituição Federal de 1988.

A edificação de uma sociedade justa passa, inexoravelmente, pela valorização do ser humano, simplesmente por assim se definir, não importando raça, cor, etnia, sexo, ou outras diferenças que possam acometer o indivíduo. Nesta senda, a valorização dos cidadãos nos dias atuais começa reemergir, ou seja, torna-se uma preocupação universal, preocupação esta que estava até pouco tempo escondida dos holofotes das 
autoridades que possuem o poder de buscar um propósito renovado para amparar os menos favorecidos, no que tange ao exercício de seus direitos. (HIPPLER, 2015, pág. 34)

No viés do bem-estar social, surgiram as políticas afirmativas a partir de demandas significativas da coletividade de forma a inserir os que estão à margem da sociedade. As conjunturas históricas remetem à escravidão, exploração, discriminação e abandono de alguns grupos. As ações em prol dos oprimidos buscam contornar essas injustiças, mas é um paliativo para promover oportunidades para esses sujeitos.

O artigo $3^{\circ}$ da Constituição Federal (1988) estabelece objetivos fundamentais, entre eles: "construir uma sociedade livre, justa e solidária" e "promover o bem de todos, sem preconceitos de origem, raça, sexo, cor, idade e quaisquer outras formas de discriminação". No entanto, os direitos conquistados no texto, devem ser reconhecidos na prática; logo, as decisões políticas bem articuladas aumentam as possibilidades de inclusão dos marginalizados.

De acordo com Hippler (2015), as discussões acerca da cidadania, no Brasil, intensificaram-se na década de 60. A partir daí, os paradigmas sociais vêm sofrendo alterações tanto em relação à evolução da sociedade quanto à adaptação das normas e leis do Direito no espaço e tempo. Assim, o bem-estar do ser humano, que depende de, no mínimo, condições básicas de sobrevivência e garantia de seus direitos e deveres, implica a inclusão social. No entanto, a monopolização do país pelo capital estrangeiro e as disparidades sociais aumentaram com a globalização, visto que os agentes de mercado visam à lucratividade, aproveitando-se das fragilidades de uma parcela significativa da sociedade com o incentivo ao consumismo, exploração de mão de obra, bem como a destruição do meio ambiente.

A fim de buscar alternativas que diminuíssem essas diferenças, nas duas últimas décadas, surgiram alguns programas, na área da educação, importantes para a inclusão como o Programa Universidade para Todos (PROUNI), o Financiamento Estudantil (FIES), a Reestruturação e Expansão das Universidades Federais (REUNI), o Fundo Nacional de Desenvolvimento da Educação (FNDE), o Programa Nacional de Acesso ao Ensino Técnico e Emprego (PRONATEC), Exame Nacional do Ensino Médio (ENEM), o Exame Nacional de Desempenho dos Estudantes (ENADE), Sistema de Seleção Unificada (SISU), a Lei de Cotas (Lei 12.711/2012), bem como outras mudanças significativas no ensino básico. Essas transformações fizeram com que as universidades se "abrissem" para as camadas mais populares da sociedade, mudando o perfil dos estudantes universitários.

Para Oliveira (2016), as políticas afirmativas (também chamadas de políticas de ação afirmativa ou ações afirmativas) estão entre as políticas sociais compensatórias com o intuito 
de garantir direitos não cumpridos integralmente pelo Estado. É importante salientar que a Constituição Federal de 1988 é considerada o marco para as mudanças sociais no país, uma vez que incitou grupos, principalmente das universidades públicas, a se voltarem às questões relacionadas às ditas "minorias".

As políticas sociais podem ser entendidas como as de educação, habitação, saúde, assistência social, previdência social, entre outras e são direcionadas a fatores econômicos. Conforme Oliveira (2016),

A política social tem um recorte de classe social. A questão social, nesse cerne, como conceito, tem um enfoque político muito específico e determina também a forma como devemos encarar as condições sociais; recorta sob o viés marxista a realidade social, fazendo com que as questões de gênero, étnico-raciais, de sexualidade e todas as questões relacionadas a posições identitárias possam ser interpretadas também como fruto de desigualdades econômicas. (pág. 43)

Dessa maneira, pode-se justificar as PA a partir de um entendimento de que é uma forma de justiça social, tendo o escopo de diminuir as desigualdades e construir uma sociedade com valores culturais diversificados. O Estado, por sua vez, não tem apenas o papel de redistribuir bens e serviços, deve também reconhecer outras perspectivas além das normalizadas durante séculos no Brasil.

\subsection{Os Núcleos de Atendimento do Ifsul - Câmpus Pelotas}

Da observação da comunidade acadêmica, da curiosidade sobre o funcionamento das atividades e do desejo de conhecer as políticas voltadas ao respeito das diversidades no Instituto Federal de Educação Ciência e Tecnologia Sul-rio-grandense, foi se construindo o objeto da presente pesquisa. Conforme o site do IFSul,

a Instituição reúne elementos singulares para a definição de sua identidade, assumindo papel representativo de uma verdadeira incubadora de políticas sociais, uma vez que constrói uma rede de saberes que entrelaça cultura, trabalho, ciência e tecnologia em favor da sociedade (IFSUL, 2019).

Para entender os processos que estão ocorrendo no IFSul, vale ressaltar a institucionalização dos Institutos Federais, uma vez que, com a reformulação da Rede Federal, no início do século XXI, os antes CEFETs, Centros Federais de Educação Tecnológica, ampliaram as etapas de ensino.

Com essa reestruturação, o projeto pedagógico que ofertava, em essência, a formação profissional em nível médio e tecnológico modificou-se para um projeto com maior amplitude através dos IFs, os quais devem ofertar a formação profissional desde a Educação Básica, através do Ensino Médio articulado ao ensino técnico, Educação Superior (licenciaturas, bacharelados e tecnólogos), pós- graduação lato sensu e stricto sensu, cursos de curta duração de Formação Inicial e Continuada, reunindo ensino, pesquisa e extensão. Com isso, e por seu elevado grau de autonomia, os IFs são equivalentes às Universidades. A partir dessa nova configuração, os Institutos Federais estão diante de novos desafios que também geram muitas expectativas (ROCHA, 2016, pág. 18). 
Rocha (2016) discorre sobre a transição dos Centros Federais de Educação Tecnológica - CEFETs, de agrotécnicas e escolas agrícolas vinculadas às universidades para Institutos Federais (IFs), em 2008, como reestruturação e expansão da Rede Federal, estabelecido pela Lei $\mathrm{n}^{\mathrm{o}} 11.892$, de 29 de dezembro de 2008. Nesse contexto, os IFs começaram a ofertar a formação profissional desde a Educação Básica até a pós-graduação lato sensu e sctricto sensu, tornando-se equivalentes às universidades.

Segundo o site do IFSul, a instituição começou sua trajetória em 1917 com a fundação da Escola de Artes e Officios, que tinha o objetivo de atender meninos de baixa renda, através de ações da diretoria da Bibliotheca Pública Pelotense, doações da comunidade e de um terreno cedido pelo município. Em 1930, passa a ser Escola Technico-Profissional, aumentando seus cursos profissionalizantes. Depois de uma década, o prédio foi demolido e, em 1942, foi criada a Escola Técnica de Pelotas (ETP) em razão do Decreto-lei $\mathrm{n}^{\circ} 4.127$ assinado pelo então presidente Getúlio Vargas e pelo ministro da Educação Gustavo Capanena, vindo a iniciar suas atividades letivas em 1945. A ETP passa a ser uma autarquia federal em 1959, com a denominação de Escola Técnica Federal de Pelotas (ETFPEL).

A partir de 1998, começa a atuar também no nível superior de ensino com a implantação do Programa Especial de Formação Pedagógica. A transformação da ETFPEL em Centro Federal de Educação Tecnológica de Pelotas, CEFET-RS, em 1999, abriu espaço para cursos superiores de graduação e pós-graduação para, então, em 29 de dezembro de 2008, tornar-se o Instituto Federal de Educação, Ciência e Tecnologia Sul-rio-grandense nos termos da Lei $\mathrm{n}^{\circ} 11.892$.

Atualmente, a instituição é composta de dez Cursos Técnicos (nas modalidades concomitante, subsequente e integrado), oito Cursos de Graduação (licenciatura, bacharelado e tecnólogo), três Cursos de Pós-graduação Lato Sensu e dois Cursos de Pós-graduação Stricto Sensu, os quais atendem aproximadamente 5000 discentes. Essa entidade apresenta como missão "implementar processos educativos, públicos e gratuitos de ensino, pesquisa e extensão, que possibilitem a formação integral mediante o conhecimento humanístico, científico e tecnológico e que ampliem as possibilidades de inclusão e desenvolvimento social (IFSUL, 2019)".

A partir da Constituição Brasileira, do Estatuto da Criança e do Adolescente (Lei 8.069/90), da Lei de Diretrizes e Bases da Educação (9394/96) e da Lei 10.098 de 19 de dezembro de 2000 (promoção da acessibilidade das pessoas portadoras de deficiência ou com mobilidade reduzida), a acessibilidade foi regulamentada no país. Porém, foi com o TEC NEP, Programa Educação Tecnológica e Profissionalização para Pessoas com Necessidades 
Especiais, também no ano de 2000, desenvolvido pelas Secretarias de Educação Especial (SEESP) e a Secretaria de Ensino Médio e Tecnológico (SEMTEC) do MEC, que houve a consolidação de uma proposta efetiva envolvendo núcleos específicos de ações afirmativas para os, então, CEFETs.

A grande questão, para Rocha (2016), é o desafio da inclusão de pessoas com deficiência, considerando a acessibilidade e a aprendizagem, e os Núcleos de Apoio às Pessoas com Necessidades Específicas, NAPNEs, criados com esse intuito, seriam o aporte para essas ações. No entanto, apesar de existir o programa em todos os Campi, cada IF tem o poder de desenvolver seu próprio planejamento institucional. Assim, os Planos de Desenvolvimento Institucionais (PDIs) são a operacionalização das políticas educacionais no nível macro, mas que, na perspectiva do microcontexto institucional, são reinterpretadas de acordo com interesses e necessidades locais.

Com isso, ainda no antigo CEFET, em 2008, foi criado o NAPNE, definido como um órgão de assessoramento da Pró-Reitoria de Ensino e da Direção Geral do Câmpus Pelotas. Antes mesmo do Decreto 7.611/2011 que o institucionalizou, já em 2008 havia uma comissão de servidores trabalhando em prol das políticas públicas inclusivas. Em novembro do mesmo ano, ocorreu o $1^{\circ}$ Ciclo de Palestras com o nome de INCLUSÃO $x$ PROFISSIONALIZAÇÃO: Um desafio para o ensino profissionalizante no CEFET-Pelotas. O objetivo do evento se justificava a partir da proposta de, em 2009, receber, como alunos regulares dos cursos técnicos, tecnológicos e na formação continuada de trabalhadores, alunos portadores de necessidades educacionais especiais. O núcleo presta serviços de apoio a estudantes e servidores e tem a função de aprimorar condições de acessibilidade e permanência. Dentre outras demandas, estão as orientações para adaptações curriculares, inclusão e permanência social de grupos que apresentem alguma deficiência física e/ou intelectual.

Nesse mesmo período, foi criado o NEABI, Núcleo de Estudos Afro-brasileiros e Indígenas, que desenvolve ações de gestão, ensino, pesquisa e extensão referentes à temática das relações étnico-raciais. E, posteriormente, O NUGED, Núcleo de Gênero e Diversidade, tem como objetivo principal diminuir a intolerância relacionada a gênero e à orientação sexual.

Em 2016, o regulamento da Política de Inclusão e Acessibilidade do IFSul foi instituído para que haja a efetivação de "ações de inclusão nas atividades de Ensino, Pesquisa e Extensão, para a promoção do respeito à diversidade socioeconômica, cultural, étnico-racial, de gênero e para pessoas com deficiência e defesa dos direitos humanos" (IFSUL, 2016). Os 
planos do documento apresentam, a partir da implantação dos Núcleos de Atendimento, o estímulo de ações afirmativas na instituição por meio de projetos, pesquisa, discussões, convênios, entre outros.

A partir da última gestão diretiva do IFSul Câmpus Pelotas, criou-se, em 2017, um espaço com grande visibilidade para os três núcleos desenvolverem seu trabalho. Em razão de a pesquisa estar em progresso, ainda há pouco material das atividades. Já houve conversas informais, com membros e ex-membros, para entender os movimentos e práticas desses núcleos e conseguir registros das ações desenvolvidas.

\section{Considerações Finais}

Entende-se a escola como uma das instituições regulamentadoras do Estado que tem o intuito do bem-estar, mas também do controle social. À luz da busca da individualidade e da autonomia, a inclusão e aceitação das diversidades torna-se, na teoria, uma realidade possível. No entanto, a ideia de inclusão pressupõe que, a priori, existem alguns grupos que não estão dentro dos padrões considerados normais ou socialmente aceitos ao longo da história. Nesse contexto, as ações afirmativas também são carregadas de relações de poder, uma vez que os grupos socialmente excluídos serão regulados por outros.

As atuais políticas voltadas às minorias convivem com discursos anteriores, e essa disputa traz, não raras vezes, conflitos entre discursos. Assim, com a institucionalização dos Núcleos de Atendimento, tanto pode haver acomodação como resistência às mudanças, sejam elas impostas ou trabalhadas e discutidas de forma ampla e democrática. A descentralização de decisões é outro ponto essencial para a constituição desses núcleos como forma de problematizar as políticas públicas a fim de aperfeiçoar decisões dentro do âmbito da educação.

Ainda que a questão da normalidade $\mathrm{x}$ anormalidade faça parte de uma ordem social que resiste em razão de normas e de discursos passados, no espaço escolar, a incorporação de novos sentidos pode ganhar significação quando é um repertório partilhado pela comunidade, produzido a partir do diálogo de seus indivíduos.

Em relação aos trabalhos acadêmicos estudados, podem-se observar dados significativos sobre os NAPNEs, que trabalham para a inclusão de alunos portadores de deficiência, e sobre os NEABIs, cujo objetivo é a inclusão de alunos negros e indígenas. No entanto, em nenhum dos trabalhos apareceu o NUGED, que trabalha a inclusão das diversidades sexuais e de gênero. 
Percebe-se que a própria história do Instituto Federal Sul-rio-grandense, constituída em razão dos movimentos políticos que aconteceram primeiramente em um contexto local para, em outro momento, tornar-se uma autarquia federal, demonstra o quanto a efetivação de políticas depende de vários fatores e deve ser analisada de acordo com os atores envolvidos no processo. Dessa maneira, ainda que as políticas afirmativas no âmbito da educação surjam, a partir de articulações na macropolítica (tanto nacionais quanto internacionais), não são fixas e imutáveis.

A abordagem teórico-metodológica do ciclo de políticas é um recurso para examinar essas políticas e investigar o Contexto da Prática, uma vez que a recriação e reinterpretação das PA, dentro da instituição, são discutidas de acordo com os atores envolvidos no processo e são o foco da pesquisa. Após a realização e análise das entrevistas, pretende-se evidenciar as ações dos participantes envolvidos diretamente na organização e planejamento dos Núcleos de Atendimento, seus interesses, suas formas de atuação, suas reflexões sobre a prática, bem como seus posicionamentos frente às demandas que surgem e expectativas com o trabalho do grupo e o envolvimento da comunidade.

Nesse sentido, o referencial teórico escolhido pode contribuir para a análise de dados, considerando fatores macro e micro e suas interações. Além disso, auxiliará na compreensão de quais são as negociações, conflitos, influências e estratégias para as decisões e ações que envolvem discentes e servidores. Por isso, essa perspectiva de estudo poderá apresentar de forma mais expressiva as ações desenvolvidas dentro do ambiente. A partir das políticas educacionais voltadas para as minorias, perceber a reestruturação da cultura escolar e das concepções de identidade na escola, detectando os principais problemas que envolvem a diversidade.

\section{Referências}

BALL, Stephen. Education Reform: a critical and post-structural approach. Buckingham: Open University Press, 1994.

BALL, Stephen. Performatividade, privatização e o pós-Estado do Bem-Estar. Educ. Soc. [online]. 2004, vol.25, n.89, pp. 1105-1126. ISSN 0101-7330.

BOGDAN, Roberto C.; BIKLEN, Sari Knopp. Investigação qualitativa em educação. Tradução Maria João Alvarez, Sara Bahia dos Santos e Telmo Mourinho Baptista. Porto: Porto Editora, 1994.

BRASIL. Constituição Federal de 1988. Promulgada em 5 de outubro de 1988. Disponível em <http://www.planalto.gov.br/ccivil_03/constituicao/constituição.htm>. Acesso em: 15. dez. 2019. 
BRASIL. Instituto Federal Sul-rio-grandense. Disponível em: <http://www.ifsul.edu.br/instituto>. Acesso em: 03.out.2019.

BRASIL. Ministério da Educação. Secretaria de Educação Profissional e Tecnológica. Programa TEC NEP - Educação, Tecnologia e Profissionalização para Pessoas com Necessidades Educativas Especiais. Brasília, DF, 2000a.

Declaração mundial sobre educação para todos. Plano de ação para satisfazer as necessidades básicas de aprendizagem. Tailândia, 1990.

FOUCAULT, M. O sujeito e o poder. In: Hubert L. Dreyfus e Paul Rabinow. MICHEL FOUCAULT. Uma Trajetória Filosófica. Para além do estruturalismo e da hermenêutica. $2^{\mathrm{a}}$. Edição Revista. Tradução de Vera Portocarrero e Gilda Gomes Carneiro. Introdução: Traduzida por Antonio Cavalcanti Maia. Revisão técnica de Vera Portocarrero. Coleção Biblioteca de Filosofia. Coordenação editorial: Roberto Machado. Rio de Janeiro: Forense Universitária, 2009.

HIPPLER, Aldair. Políticas públicas, ações afirmativas e a efetivação dos Direitos Humanos / Aldair Hippler. Orientado por: Mateus de Oliveira Fornasier. Ijuí: UNIJUÍ, 2015.

HÜSKEN, Rosane Bom. Paradigma Inclusivista. Pelotas: Universidade Católica de Pelotas, 2000 (Curso de Educação Especial a Distância - Módulos).

IFSUL. Resolução $n^{\circ}$ 51/2016. Regulamento da Política de Inclusão e Acessibilidade do IFSul. Disponível em: 〈HTTP://www.ifsul.ifsul.edu.br/2016/item/241〉 - resolução - 512016. Acesso em: 07.10.2019.

Lei ${ }^{\circ}$ 11.892, de 29 de dezembro de 2008. Institui a Rede Federal de Educação Profissional, Científica e Tecnológica, cria os Institutos Federais de Educação, Ciência e Tecnologia, e dá outras providências. Brasília, DF, 2008. Disponível em: <http://www.planalto.gov.br/ccivil_03/_ato2007-2010/2008/lei/111892.htm>. Acesso em: 02. dez. 2019.

MAINARDES, Jefferson. Abordagem do Ciclo de Políticas: uma Contribuição para a Análise de Políticas Educacionais. Educação \& Sociedade, Campinas, vol. 27, n. 94, p. 4769, jan./abr. 2006.

MINAYO, M. C. S. Técnicas de pesquisa: entrevista como técnica privilegiada de comunicação. In:____ O desafio do conhecimento: pesquisa qualitativa em saúde. 12. ed. São Paulo: Hucitec, 2010. p. 261- 297.

MORAES, R.; GALIAZZI, M. C. Análise textual discursiva. 3. ed. Revisada e Ampliada. Ijuí: Editora Unijuí, 2016.

OLIVEIRA, Valéria dos Santos. Entre desafios e oportunidades: análise da política afirmativa educacional superior indígena na UFPR / Valéria dos Santos de Oliveira, orientador Rodrigo Rossi Horochovski - Paraná: UFPR, 2016. 
ROCHA, Vânia Meneghini da. A educação especial nos institutos federais: o que dizem os planos de desenvolvimento institucionais? / Vânia Meneghini da Rocha; orientadora Dra. Rosânia Campos, co-orientadora Dra. Aliciene Fusca Machado Cordeiro- Joinville: UNIVILLE, 2016. 